\title{
Hospitalization among prevalent hemodialysis patients: one year retrospective study
}

\author{
Hisham Mohamed El Sayed* , Ahmed Shabaan*, Maha Behairy*', Azza M. Hassan** \\ *Internal Medicine and Nephrology department, faculty of medicine, Ain Shams \\ University. \\ ** Community, Environmental and Occupational Medicine department, faculty of medicine, \\ Ain Shams University.
}

Received: 4-7-2015, accepted:3-12- 2015

\begin{abstract}
Background: Incidence of hemodialysis as renal replacement therapy has been increasing continuously in the last decades in Egypt. The risk of hospitalization increases among hemodialysis patients due to factors related to hemodialysis, vascular access or comorbid conditions. Objectives: To measure the frequency and identify the causes of hospital admission among chronic hemodialysis patients and identify factors affecting duration of their hospital stay. Patients and methods: The study population consisted of End Stage Renal Disease (ESRD) patients on regular hemodialysis for more than six months. Total number of patients was 792 recruited from nine different hemodialysis centers in Egypt. A descriptive study was carried out using hospital records for the year 2012. Data extraction sheet was designed to collect data from records as personal data, medical history and laboratory results. Results: Three hundreds and eighty eight patients (49\%) had history of hospital admission at least once during the study period. The most frequent cause of hospital admission was complicated A-V fistula in 128 (33\%) of the patients followed by disturbed conscious level in $82(21.1 \%)$. No significant difference was found between admitted and non-admitted groups except for type of dialysate used $(P$ value $<0.01)$, vascular access $(P$ value $<0.01)$, presence of hypertension $(P$ value $<0.05)$, presence of ischemic heart disease $(P$ value $<0.01)$, age of patients $(P$ value $<0.05)$ and mean Ca level $(P$ value $<0.05)$. Logistic regression analysis for determinants of hospital admission showed that decreased mean $\mathrm{Ca}$ level, using Catheter as a vascular access, using acetate as dialysate, presence of hypertension and presence of ischemic heart disease were significant predictors of hospital admission among hemodialysis patients. The median duration of hospital stay was 7 days with (2-7 IQR), 35 (9.02\%) of hospitalized patients had a duration of hospital stay of more than 7 days and no statistically significant difference was found between them and the other hospitalized patients regarding studied parameters except for surface area of dialyzer $(P$ value $<0.05)$. Conclusion: High rate of hospitalization among Egyptian patients on regular hemodialysis especially with complicated AVF as the main cause of admission that increases patient morbidity and financial burden on health care services, needs an integrated vascular management in hemodialysis centers and further studies to determine a comprehensive evidence-based management policy for hemodialysis patients in Egypt .
\end{abstract}

Keywords: Hemodialysis, vascular access, dialysate, hospital admission. *corresponding author, Email: drazzahassan@yahoo.com (Azza M. Hassan)

\begin{tabular}{lllll}
\hline The Egyptian Journal of Community Medicine & Vol. 34 & No. 2 & April & 2016
\end{tabular}




\section{Introduction:}

ESRD is one of the main health problems in Egypt. ${ }^{(1)}$ The prevalence of ESRD in Egypt increased from 225 per million population (pmp) in 1996 to $483 \mathrm{pmp}$ in 2004 .The main cause of ESRD in Egypt is hypertension followed by diabetes and still unknown causes represent about 15\%. ${ }^{(2)}$ Hospitalization among hemodialysis patients may be caused by inadequate dialysis leads to serious conditions (e.g.,hyperkalemia , metabolic acidosis, volume overload) or in some cases hospitalization is to treat a preexisting co-morbid condition (e.g., cardiovascular complications, anemia, infection, renal osteodystrophy, vascular access complications).

Measurement of hospitalization in the dialysis population is an important indicator of patient morbidity and quality of life as well as the cost of treatment among dialysis patients. In the United States, dialysis patients are admitted to the hospital approximately twice a year and spend an average of 12 days in the hospital per year. ${ }^{(3)}$ The main problem in developing countries is lack and inaccuracy of data registry. Also there are no available epidemiological reports for different parts of the country. ${ }^{(4)}$ This study aims to assess the frequency of hospital admission and identify the related causes that might increase the rate of hospital admissions or the length of stay in hospital among ESRD patients on regular hemodialysis (HD) .

\section{Patients and methods:}

The study population consisted of ESRD patients on regular HD for more than six months. Needed sample size was 384 patients putting in consideration hospital admission rate of $50 \% \pm 5 \%$ at $95 \%$ C.I using Epi Info7 program. Total number of patients records used was 792 recruited from nine different hemodialysis centers in Cairo, Egypt. These centers are considered referral centers for ESRD patients from different areas allover Egypt: (Nile hospital , Bahteem hospital , Shobra hospital, Naser hospital, Mandera hospital, kaluob hospital , Harm center, Sherief center and Gomherya center). An approval was taken from the dialysis centers included in the study before starting data collection. A descriptive study carried out using hospital records for the year 2012. Data extraction sheet was designed to collect data from records, available data were collected including personal data as age and sex, cause of renal failure, presence of co-morbidities, duration of HD , type of dialyzer, dialysate, vascular access, , history of hospital admission, duration of hospital stay and causes of hospital admission. Routine laboratory results were recorded as hemoglobin level, serum creatinine, blood urea, calcium, phosphorous, sodium and potassium levels. Virology results as $\mathrm{HCV} \mathrm{Ab}, \mathrm{HBVsAg}$, and HIV $\mathrm{Ab}$. Analysis of data was done by IBM computer using SPSS (Statistical Program for Social Science) version 18. Quantitative data were presented as minimum, maximum, mean and SD.Qualitative data were presented as number and percent. Chi-square test was used to compare qualitative variables between groups. Student t-test was used to compare quantitative variables between two groups. One way ANOVA (analysis of variance) test was used to compare quantitative variables between more than two groups. Logistic regression analysis was used for determinants of hospital admission. $P$

No. 2

April

2016 
value less than 0.05 was considered statistically significant.

\section{Results:}

Total number of patient's records were 792 records. The patient's age was ranging between 16 and 79 years old with mean of $55.68 \pm 9.62$ years. Duration of hemodialysis was ranging between six months and 21 years with mean of 4.53 years and SD of 3.09 years. $499(63 \%)$ of patients were males and $663(83.7 \%)$ were married. The most frequent cause of renal failure was hypertension in 343 $(43.3 \%)$ followed by diabetic nephropathy in 233 (29.4\%). Most of patients $775(98 \%)$ were using A-V fistula as a vascular access , $612(77.3 \%)$ of patients were using bicarbonate as dialysate and $683(86.2 \%)$ were using a dialyzer of surface area (SA) and flux (130-low flux). All patients were receiving 3 sessions per week of $4 \mathrm{~h}$ duration per session. Among the studied patients 713 (90\%) had co-morbid conditions where 423 (53.4\%) of patients had hypertension, $252(31.8 \%)$ had diabetes and 39 (4.9\%) had ischemic heart disease (ISHD). 388 (49\%) of patients were admitted to hospital at least once during the study period (382 patients had single admission and 6 patients had frequent admission) (Table 1 and Figure $1)$. The most frequent cause of hospital admission was complicated $\mathrm{A}-\mathrm{V}$ fistula (33\%) [99 (25.4\%) thrombosis of AVF, $25(6.4 \%)$ infected AVF and A-V aneurysm in $3(0.8 \%)$ ], followed by disturbed conscious level (21.1\%) [22(5.7\%) due to hypertensive encephalopathy, $32 \quad(8.2 \%)$ uremic encephalopathy, 15 (3.9\%) hepatic encephalopathy and cerebro-vascular stroke in 13 (3.3\%)] (Figure 2). No significant association was found between patient's characteristics and hospital admission except for type of vascular access (catheter in $3.6 \%$ of admitted group versus $0.5 \%$ of nonadmitted), type of dialysate (acetate was used in $35.6 \%$ of patients in admitted group versus $10.4 \%$ in non-admitted group ) $(P$ value <0.01), percent of patients with hypertension $(57.7 \%$ of admitted group versus $49.3 \%$ of nonadmitted) ( $P$ value <0.05), percent of patients with ischemic heart disease $(8 \%$ of admitted group versus $2 \%$ of nonadmitted) $(P$ value $<0.01)$ and age of patients where mean age of admitted patients was higher than that of nonadmitted (56.5 years versus 54.9 years respectively) ( $P$ value $<0.05$ ) (Table 2$)$. Regarding laboratory results, no significant difference was found between admitted and non-admitted group except for the mean $\mathrm{Ca}$ level where its mean was lower in admitted group compared to non-admitted group $(8.4$ versus 8.6 respectively) ( $P$ value $<0.05$ ) (Table 3 ). Logistic regression analysis for determinants of hospital admission showed that decreased mean Ca level, using Catheter as a vascular access, using acetate as dialysate, presence of hypertension and presence of ischemic heart disease were significant predictors of hospital admission among HD patients (Table 4). Regarding duration of hospital stay, the median duration of hospital stay was 7 days with (2-7 IQR). To know the factors that may affect duration of hospital stay, we divided patients with history of hospital admission into two groups: those hospitalized for 7 days or less represent $(90.98 \%)$ of hospitalized patients and those hospitalized for more than 7 days represent $(9.02 \%)$ of hospitalized patients (Figure 3). When comparing the two groups regarding different personal and laboratory data we found no statistically significant 
difference between them except for type of dialyzer used where $35(100 \%)$ of patients admitted $>7$ days were using (130-low) compared to $292(82.7 \%)$ of patients admitted $\leq 7$ days ( $\mathrm{p}$ value $<0.01$ ) (Tables 5, 6).

\section{Discussion}

We reported $49 \%$ of 792 ESRD patients on regular hemodialysis were admitted to hospital at least once during the study period, this high rate reflect increased healthcare services costs needed.

In comparison to (Quinn et al, 2014) study, who reported total hospitalizations $153(73.9 \%)$ of the 207 Canadian ESRD patients on HD dialysis, with at least 1 hospitalization. (5)

Another study by (Hassanien et al, 2014) observed retrospectively 208 (65.4\%) of 318 hemodialysis patients were hospitalized at least once in one of the Ministry of Health Hospitals in Makkah, Saudi Arabia. ${ }^{(6)}$

We studied different indications for hospitalization among HD patients and we observed that the most frequent cause was complicated AVF in $33 \%$ of the patients, included AVF thrombosis, infection or aneurysm. $21 \%$ of patients admitted with disturbed conscious level due to hypertensive encephalopathy, uremic or hepatic encephalopathy or cerebrovascular stroke. Cardiovascular complications (acute coronary syndrome and cardiac arrhythmia) were the causes of admission in $11.6 \%$.

In agreement with (Mohamed et al, 2005) study on hospitalization conducted in AlMadinah City also reported that vascular access-related problems as the primary reason in $33.6 \%$, followed by infectious disease in $31.2 \%$ and cardiovascular disease in $18.4 \%$ of studied HD patients. ${ }^{(7)}$

On the other hand (Hassanien et al, 2014) observed that the most frequent reasons for hospitalization in single center were diseases of the genitourinary system $(40.1 \%)$, diseases of the circulatory system (22.6\%) and vascular access (19.5\%), followed by overall infectious diseases $(9 \%)$. ${ }^{(6)}$

In contrast to (Vaiciuniene et al, 2005) study, the most frequent causes of hospitalization were cardiovascular diseases (25\%), infections (22\%), and access related complications (10\%) among 187 ESRD on regular HD during one year . (FALK et al., 2000) study also considered cardiovascular or peripheral vascular complications as the main reasons for hospitalization among HD patients. ${ }^{(8)}$ The mean of age of patients and the frequency of comorbid conditions especially ISHD in these studies were higher than our patients, which may explain the differences to our results.

Vascular access continues to be a leading cause for hospitalization and morbidity in patients on HD. (9) In our study, complicated AVF was the main cause of hospitalization. The most common cause of vascular access thrombosis is venous neointimal proliferation which causes stenosis, leading to fistula thrombosis ${ }^{(10)}$. $\mathrm{AV}$ access thrombosis may be also related to age (11) and the co-morbid diseases as diabetes mellitus and ischemic heart disease, insufficient anticoagulation, and also hypertension with excessive ultrafiltration leading to more hypotension episodes that may precipitate to venous thrombosis ${ }^{(12)}$. Venous catheter was a significant predictor for hospitalization by logistic 
analysis that agree with many studies reported that catheters remain associated with the greatest hospitalization risk among hemodialysis patients $(13,14,15)$, that may be related to vascular access related infection or thrombosis. (Lacson et al., 2010) ${ }^{(15)}$ study reported also that catheters associated with high CRP titer and inflammation even in absence of overt infection perhaps as foreign body or because of biofilm.

We observed that acetate dialysate had significant association to hospitalization, may be due to problems triggered by acetate include cytokine production with higher microinflammation, dyslipidemia, arterial hypotension, and myocardial dysfunction with a rise in troponin. As acetate dialysate is cheaper than bicarbonate, some centers in Egypt still using acetate (10)

Age ${ }^{(6)}$ and high prevalence of comorbid condition particularly cardiovascular disease (17) increase the risk of hospitalization among hemodialysis patients .Through our study we found that patients who were older or had a comorbidity as hypertension or ISHD, had significant associations to hospital admission.

We reported also that hypocalcemia was a significant predictor for hospital admission among hemodialysis patients. Chronic hypocalcemia is independently associated with morbidity and mortality in ESRD patients. ${ }^{(18)}$ But we didn't find significant correlation between hospital admission and phosphorous level or PTH, this against (Geofrey et al., 2004) who found that hyperphosphatemia and hyperparathyroidism were associated with hospitalization among HD patients (19)
In this study the median duration of hospital stay was 7 days with (2-7 IQR), $9.02 \%$ only of hospitalized patients had more than 7 days hospital stay. In comparison to (Hassanien et al, 2014) study who reported that length of stay in hospital ranged between one and 80 days per hospital admission with a median of three days per admission.$^{(6)}$ other studies reported 19 days ${ }^{(5)}, 6.3$ days as average length of hospital stay among hemodialysis patients ${ }^{(20)}$

We studied different factors related to patient and dialysis that may affect length of hospital stay, only lower dialyzer surface area had statistically significant association to prolonged duration of hospital stay that may reflect inadequate dialysis of patients, which need improvement of quality of health care management for hemodialysis patients.

\section{Conclusion:}

High rate of hospitalization among Egyptian patients on regular hemodialysis especially with complicated $\mathrm{AVF}$ as the main cause of admission that increases patient morbidity and financial burden on health care system.

\section{Recommendations}

An integrated vascular management should be employed in hemodialysis centers as regard screening of vascular access integrity and early management of the complications. Nephrologist should be trained on professional arteriovenous fistula management. Further researches are needed to study indications of hospitalization among hemodialysis patients to determine a comprehensive evidence-based management policy for hemodialysis patients in Egypt.

\section{References}


1) Ahmed AM, Allam MF, Habil ES, Metwally AM, Ibrahim NA, Radwan M, El-Gaafary MM, Afifi A, Gadallah MA. 2010. Development of practice guidelines for hemodialysis in Egypt Indian J Nephrol.; 20(4): 193-202.

2) Afifi A. (2008): The Egyptian Renal Registry, The $9^{\text {th }}$ annual report for the year 2008.

3) Collins $\mathbf{A} \mathbf{J}^{\mathbf{1}}$, Foley $\mathbf{R N}$, Chavers B, Gilbertson D, Herzog C, Johansen K, Kasiske B, Kutner N, Liu J, St Peter W, Guo H, Gustafson S, Heubner B, Lamb K, Li S, Li S, Peng Y, Qiu Y, Roberts T, Skeans M, Snyder J, Solid C, Thompson B, Wang C, Weinhandl E, Zaun D, Arko C, Chen SC, Daniels F, Ebben J, Frazier E,Hanzlik C, Johnson R, Sheets D, Wang X, Forrest B, Constantini E, Everson S, Eggers P, Agodoa L. US renal data system 2011 annual data report. Am J Kidney Dis 2011; 59: A7.

4) Reikes ST. 2000. Trends in end-stage renal disease. Epidemiology, morbidity, and mortality .Postgrad Med.; 108(1):124-6, 129-31, 135-6 .

5) Quinn RR, Ravani P, Zhang X, Garg A, Blake PG, Austin PC, Zacharias JM, Johnson JF, Pandeya S, Verrelli M, Oliver MJ.2014. Impact of modality choice on rate of modality choice on rates of hospitalization in patients eligible for both peritoneal dialysis and hemodialysis. Peritoneal Dialysis International, 34;41-48.

6) Hassanien A, Majeed A, Watt $H$. 2014. Retrospective observational study examining indications for hospitalisation among haemodialysis patients at one of the Ministry of Health Hospitals in Makkah, Saudi Arabia.Journal of the
Royal Society of Medicine Open; 5(10) $1-11$.

7) Mohamed AO.2005. Morbidity and Mortality in ESRD Patients on Regular Hemodialysis: A Single Center Experience. Saudi J Kidney Dis Transpl ,16:336-41.

8) Vaiciuniene R, KuzminskisV, Bumblyte LA. 2005. Hospitalization in hemodialysis patients in one region of Lithuania Int J Artif Organs ,28(12): 1228 - 1231 .

9) Baltimore. Centers for Medicare \& Medicaid Services: 2004 Annual Report. End-Stage Renal Disease Clinical Performance Measures Project. Department of Health and Human Services, Centers for Medicare \& Medicaid Services, Center for Beneficiary Choices.

10) Bonatti J, Oberhuber A, Schachner T, Zou Y, Hammerer-Lercher A, Mittermair R, Laufer G.2004. Neointimal hyperplasia in coronary vein grafts: pathophysiology and prevention of a significant clinical problem. Heart Surg Forum , 7:72-77.

11) Grapsa EJ, Paraskevopoulos AP, Moutafis SP, Vourliotou $\underline{\text { AJ }}$ Papadoyannakis NJ, Digenis GE, Zerefos NJ. 1998. Complications of vascular access in hemodialysis (HD) aged vs adult patients. Geriatr NephrolUrol ,8(1):21-4.

12) Schild AF .2010. Maintaining vascular access: the management of hemodialysis arteriovenous grafts. Vasc Access. Apr-Jun ;11(2):92-9.

13) Rayner H, Pisoni R, Bommer J, Canaud B, Hecking E, Locatelli F, Piera L, Bragg-Gresham JL, Feldman 
HI, Goodkin DA, Gillespie B, Wolfe RA, Held PJ, Port FK. 2004. Mortality and hospitalization in haemodialysis patients in five European countries: results from the Dialysis Outcomes and Practice Patterns Study (DOPPS). Nephrol Dial Transplant ,19: 108-120.

14) Metcalfe W, Khan IH, Prescott GJ, Simpson K, Macleod AM. 2003. Hospitalization in the first year of renal replacement therapy for end-stage renal disease. QJM. Dec;96(12):899-909.

15) Lacson E, Wang W, Lazarus J, Raymond M. Hakim. 2010. Change in Vascular Access and Hospitalization Risk in Long-Term Hemodialysis Patients. CJASN ,November ;5(11): 1996-2003

16) Bolasco P, Panichi V, Paletti S, Mancini E.2011.Will there be acetate in dialysis solutions for the foreseeable future?.G Ital Nefrol., 28(4):359-68.
17) Rostand SG. 2000. Coronary heart disease in chronic renal insufficiency: some management considerations. J Am Soc Nephrol , 11: 1948-1956.

18) Foley RN, Parfrey PS, Harrnett JD, Kent GM, Hu L, O';Dea R, Murray DC. Barre PE. 1996. Hypocalcemia, Morbidity, and Mortality in End-Stage Renal Disease. Am J Nephrol; 16:386393.

19) Block GA, KLASSEN PS, LAZARUS JM, Ofsthun N, Lowrie EG, Chertow GM. 2004. Mineral Metabolism, Mortality, and Morbidity in Maintenance Hemodialysis. J Am Soc Nephrol 15: 2208-2218.

20) Kshirsagar AV, Hogan SL, Mandelkehr L, Falk RJ. 2000. Length of Stay and Costs for Hospitalized Hemodialysis Patients: Nephrologists versus Internists. J Am Soc Nephrol , 11: 1526-1533. 
Table 1: Description of patient's characteristics (Total number =792):

\begin{tabular}{|c|c|c|c|c|}
\hline $\begin{array}{l}\text { SD } \\
9.62\end{array}$ & $\begin{array}{l}\text { Mean } \\
55.68\end{array}$ & $\begin{array}{l}\text { Maximum } \\
79\end{array}$ & $\begin{array}{l}\text { Minimum } \\
16\end{array}$ & Age in years \\
\hline 3.09 & 4.53 & 21 & 0.50 & Duration of HD* in years \\
\hline$\%$ & $\mathbf{N}$ & & & \\
\hline 63.0 & 499 & \multicolumn{2}{|l|}{ Male } & \multirow{2}{*}{ Sex } \\
\hline 37.0 & 293 & \multicolumn{2}{|l|}{ Female } & \\
\hline 83.7 & 663 & \multirow{2}{*}{\multicolumn{2}{|c|}{$\begin{array}{l}\text { Married } \\
\text { Widow }\end{array}$}} & \multirow{3}{*}{ Marital status } \\
\hline 12.9 & 102 & & & \\
\hline 3.4 & 27 & \multicolumn{2}{|l|}{ Single } & \\
\hline 43.3 & 343 & \multicolumn{2}{|l|}{ Hypertension } & \multirow{9}{*}{ Cause of renal failure } \\
\hline 3.5 & 28 & \multicolumn{2}{|c|}{ Analgesic nephropathy } & \\
\hline 4.4 & 35 & \multicolumn{2}{|c|}{ Chronic pyelonephritis } & \\
\hline 29.4 & 233 & \multicolumn{2}{|c|}{ Diabetic nephropathy } & \\
\hline 5.7 & 45 & \multirow{2}{*}{\multicolumn{2}{|c|}{$\begin{array}{l}\text { Polycystic kidney } \\
\text { Obstructive nephropathy }\end{array}$}} & \\
\hline 7.2 & 57 & & & \\
\hline 1.6 & 13 & \multicolumn{2}{|c|}{ Chronic glomerulonephritis } & \\
\hline .9 & 7 & \multicolumn{2}{|c|}{ Renal amyloidosis } & \\
\hline 3.9 & 31 & \multicolumn{2}{|l|}{ Unknown } & \\
\hline \multicolumn{5}{|c|}{ Dialysis parameters: } \\
\hline $\begin{array}{l}98.0 \\
2.0\end{array}$ & $\begin{array}{l}775 \\
16\end{array}$ & \multicolumn{2}{|l|}{$\begin{array}{l}\text { A-V fistula } \\
\text { Catheter }\end{array}$} & Vascular access \\
\hline 77.3 & 612 & \multicolumn{2}{|l|}{ Bicarbonate } & \multirow{4}{*}{$\begin{array}{l}\text { Dialysate } \\
\text { Dialyzer SA and flux }\end{array}$} \\
\hline 22.7 & 180 & \multirow{2}{*}{\multicolumn{2}{|c|}{$\begin{array}{l}\text { Acetate } \\
130-\text { low }\end{array}$}} & \\
\hline 86.2 & 683 & & & \\
\hline 13.8 & 109 & \multicolumn{2}{|l|}{ 160-low } & \\
\hline \multicolumn{5}{|c|}{ Co-morbidities: } \\
\hline 53.4 & 423 & \multicolumn{3}{|l|}{ Hypertension } \\
\hline 31.8 & 252 & \multicolumn{3}{|c|}{ Diabetes mellitus } \\
\hline $\begin{array}{l}4.9 \\
49.0\end{array}$ & $\begin{array}{l}39 \\
388\end{array}$ & \multicolumn{3}{|c|}{$\begin{array}{l}\text { Ischemic heart disease } \\
\text { Hospital admission }\end{array}$} \\
\hline
\end{tabular}

*HD: Hemodialysis 
Table 2: Relation between patients' characteristics and hospital admission:

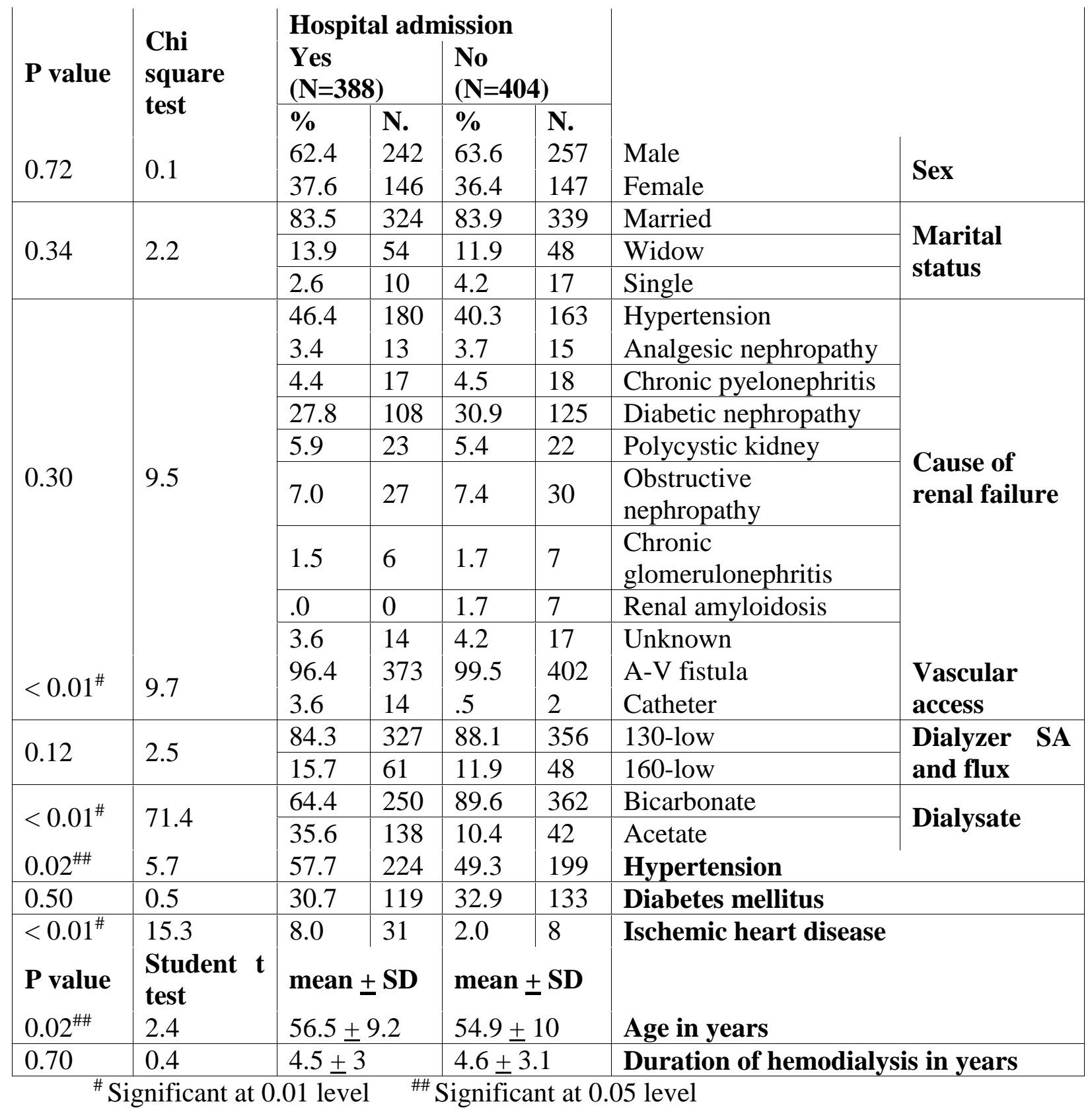


Table 3: Relation between lab results of patients and hospital admission:

\begin{tabular}{|c|c|c|c|c|c|c|}
\hline \multirow{3}{*}{$P$ value } & \multirow{3}{*}{$\begin{array}{l}\text { Chi square } \\
\text { test }\end{array}$} & \multicolumn{4}{|c|}{ Hospital admission } & \multirow{3}{*}{ Lab results } \\
\hline & & \multicolumn{2}{|c|}{$\begin{array}{l}\text { Yes } \\
(\mathrm{N}=388)\end{array}$} & \multicolumn{2}{|c|}{$\begin{array}{l}\text { No } \\
(\mathrm{N}=404)\end{array}$} & \\
\hline & & $\%$ & N. & $\%$ & N. & \\
\hline 0.22 & 1.5 & 46.6 & 181 & 51.0 & 206 & HCV positive \\
\hline 1.00 & $\begin{array}{l}0.3 \\
\text { (Fisher Exact) }\end{array}$ & 0.3 & 1 & 0.5 & 2 & HBV positive \\
\hline$P$ value & Student $t$ test & SD & Mean & SD & Mean & \\
\hline 0.59 & 0.5 & 1.5 & 9.8 & 1.6 & 9.7 & Hemoglobin \\
\hline 0.66 & 0.4 & 40.7 & 133.2 & 39.5 & 134.5 & Urea \\
\hline 0.80 & 0.3 & 5.6 & 9.0 & 5.4 & 8.9 & Creatinine \\
\hline 0.11 & 1.6 & 3.2 & 135.7 & 3.1 & 136 & Sodium \\
\hline 0.24 & 1.2 & 0.7 & 4.7 & 0.6 & 4.6 & Potassium \\
\hline $0.04^{\#}$ & 2.0 & 1.0 & 8.4 & 1.0 & 8.6 & Calcium \\
\hline 0.13 & 1.5 & 1.2 & 4.8 & 1.2 & 4.9 & Phosphates \\
\hline
\end{tabular}

${ }^{\#}$ Significant at 0.05 level

Table 4: Logistic regression analysis for determinants of hospital admission:

\begin{tabular}{|c|c|c|c|c|c|c|}
\hline \multirow{2}{*}{$P$ value } & \multicolumn{2}{|c|}{ 95\% C.I. } & \multirow{2}{*}{$\begin{array}{l}\text { Odds } \\
\text { ratio }\end{array}$} & \multirow{2}{*}{ B } & \multirow{2}{*}{\multicolumn{2}{|c|}{ Determinants of hospital admission }} \\
\hline & Upper & Lower & & & & \\
\hline 0.13 & & & 0.19 & -1.64 & Constant & \\
\hline 0.07 & 1.03 & 0.99 & 1.01 & 0.01 & Age & \\
\hline $0.03^{\#}$ & 0.98 & 0.74 & 0.85 & -0.16 & Mean Ca & \\
\hline $0.01^{\# \#}$ & 31.23 & 1.53 & $\begin{array}{l}1.00 \\
6.90\end{array}$ & 1.93 & $\begin{array}{l}\text { A-V fistula* } \\
\text { Catheter }\end{array}$ & Vascular access \\
\hline$<$ & 6.56 & 3.03 & $\begin{array}{l}1.00 \\
4.46\end{array}$ & 1.32 & $\begin{array}{l}\text { Bicarbonate* } \\
\text { Acetate }\end{array}$ & Dialysate \\
\hline $0.04^{\#}$ & 1.79 & 1.01 & $\begin{array}{l}1.00 \\
1.34\end{array}$ & 0.29 & $\begin{array}{l}\text { No* } \\
\text { Yes }\end{array}$ & Hypertension \\
\hline$<0.01^{\# \#}$ & 8.44 & 1.68 & $\begin{array}{l}1.00 \\
3.76\end{array}$ & 1.33 & $\begin{array}{l}\text { No* } \\
\text { Yes }\end{array}$ & $\begin{array}{l}\text { Ischemic hear } \\
\text { disease }\end{array}$ \\
\hline
\end{tabular}

$\mathrm{CI}=$ Confidence Interval *reference group

\# Significant at 0.05 level \# $\quad$ Significant at 0.01 level 
Table 5: Relation between some patients' characteristics and duration of hospital stay:

\begin{tabular}{|c|c|c|c|c|c|c|c|}
\hline \multirow{3}{*}{$\begin{array}{l}\mathbf{P} \\
\text { value }\end{array}$} & \multirow{3}{*}{$\begin{array}{l}\text { Chi Square } \\
\text { test }\end{array}$} & \multicolumn{4}{|c|}{ Duration of hospital stay } & & \\
\hline & & \multicolumn{2}{|c|}{$\begin{array}{l}>7 \text { days } \\
(N=35)\end{array}$} & \multicolumn{2}{|c|}{$\begin{array}{l}\leq 7 \text { day } \\
(N=353)\end{array}$} & & \\
\hline & & $\%$ & $\mathbf{N}$. & $\%$ & N. & & \\
\hline \multirow[t]{2}{*}{0.67} & \multirow[t]{2}{*}{0.2} & 65.7 & 23 & 62.0 & 219 & Male & \multirow[t]{2}{*}{ Sex } \\
\hline & & 34.3 & 12 & 38.0 & 134 & Female & \\
\hline \multirow[t]{2}{*}{0.59} & \multirow[t]{2}{*}{0.29} & 68.6 & 24 & 64.0 & 226 & Bicarbonate & \multirow[t]{2}{*}{ Dialysate } \\
\hline & & 31.4 & 11 & 36.0 & 127 & Acetate & \\
\hline \multirow[t]{2}{*}{$0.01^{\#}$} & \multirow[t]{2}{*}{7.2} & 100 & 35 & 82.7 & 292 & 130-low & \multirow[t]{2}{*}{ Dialyzer } \\
\hline & & 0 & 0 & 17.3 & 61 & 160-low & \\
\hline \multirow[t]{2}{*}{0.46} & \multirow[t]{2}{*}{0.6} & 94.1 & 32 & 96.6 & 341 & A-V fistula & \multirow{2}{*}{$\begin{array}{l}\text { Vascular } \\
\text { access }\end{array}$} \\
\hline & & 5.9 & 2 & 3.4 & 12 & Catheter & \\
\hline 0.43 & 0.6 & 51.4 & 18 & $58.4 \%$ & 206 & \multicolumn{2}{|l|}{ Hypertension } \\
\hline 0.92 & 0.01 & 31.4 & 11 & $30.6 \%$ & 108 & \multicolumn{2}{|c|}{ Diabetes mellitus } \\
\hline 0.60 & 0.3 & 5.7 & 2 & $8.2 \%$ & 29 & \multicolumn{2}{|c|}{ Ischemic heart disease } \\
\hline $\begin{array}{l}P \\
\text { value }\end{array}$ & $\begin{array}{l}\text { Student } \\
\text { test }\end{array}$ & SD & Mean & SD & Mean & & \\
\hline 0.86 & 0.2 & 9.10 & 56.77 & 9.21 & 56.48 & Age in years & \\
\hline 0.50 & 0.7 & 4.21 & 4.94 & 2.90 & 4.45 & $\begin{array}{l}\text { Duration of } \\
\text { years }\end{array}$ & modialysis in \\
\hline
\end{tabular}

\# Significant at 0.01 level

Table 6: Relation between lab results of patients and duration of hospital stay:

\begin{tabular}{|c|c|c|c|c|c|c|}
\hline \multirow{3}{*}{$P$ value } & \multirow{3}{*}{ Chi Square test } & \multicolumn{4}{|c|}{ Duration of hospital stay } & \\
\hline & & \multicolumn{2}{|c|}{$\begin{array}{l}>7 \text { days } \\
(N=35)\end{array}$} & \multicolumn{2}{|c|}{$\begin{array}{l}\leq 7 \text { day } \\
(N=353)\end{array}$} & \\
\hline & & $\%$ & N. & $\%$ & $\mathbf{N}$. & \\
\hline 0.64 & 0.2 & 42.9 & 15 & 47.0 & 166 & HCV positive \\
\hline 1.00 & $\begin{array}{l}0.1 \\
\text { (Fisher Exact) }\end{array}$ & 0 & 0 & 0.3 & 1 & HBV positive \\
\hline P value & Student $\mathrm{t}$ test & SD & Mean & SD & Mean & \\
\hline 0.65 & 0.5 & 1.7 & 9.7 & 1.5 & 9.8 & Hemoglobin \\
\hline 0.53 & 0.6 & 31.4 & 136.6 & 41.5 & 132.9 & Urea \\
\hline 0.34 & 1.0 & 16.8 & 11.5 & 2.9 & 8.7 & Creatinine \\
\hline 0.18 & 1.4 & 2.6 & 136.4 & 3.2 & 135.6 & Sodium \\
\hline 0.11 & 1.6 & 0.7 & 4.5 & 0.7 & 4.7 & Potassium \\
\hline 0.23 & 1.2 & 0.9 & 8.2 & 1.0 & 8.4 & Calcium \\
\hline 0.19 & 1.3 & 1.2 & 4.6 & 1.2 & 4.8 & Phosphates \\
\hline
\end{tabular}




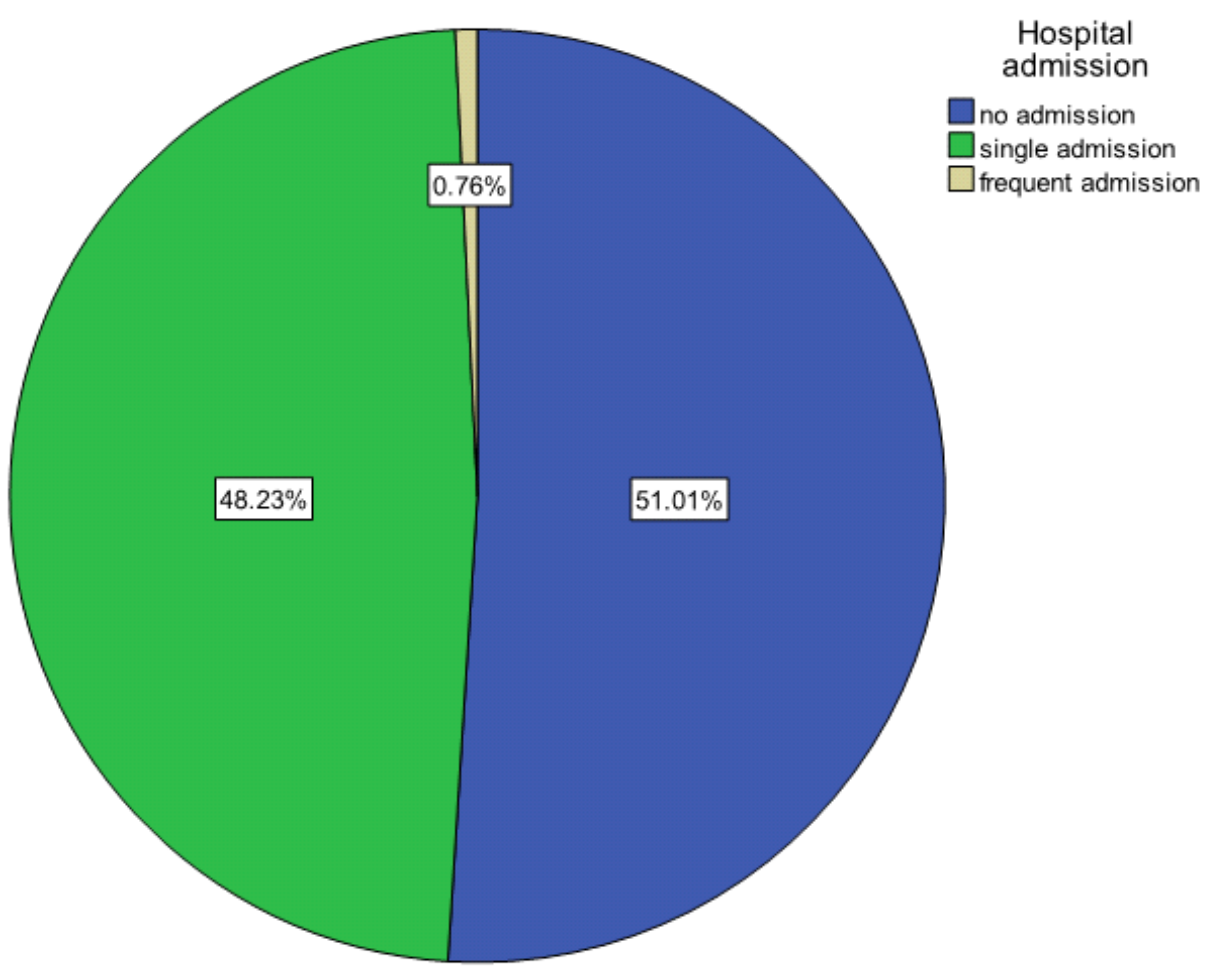

Figure 1: Frequency of hospital admission among the studied patients 


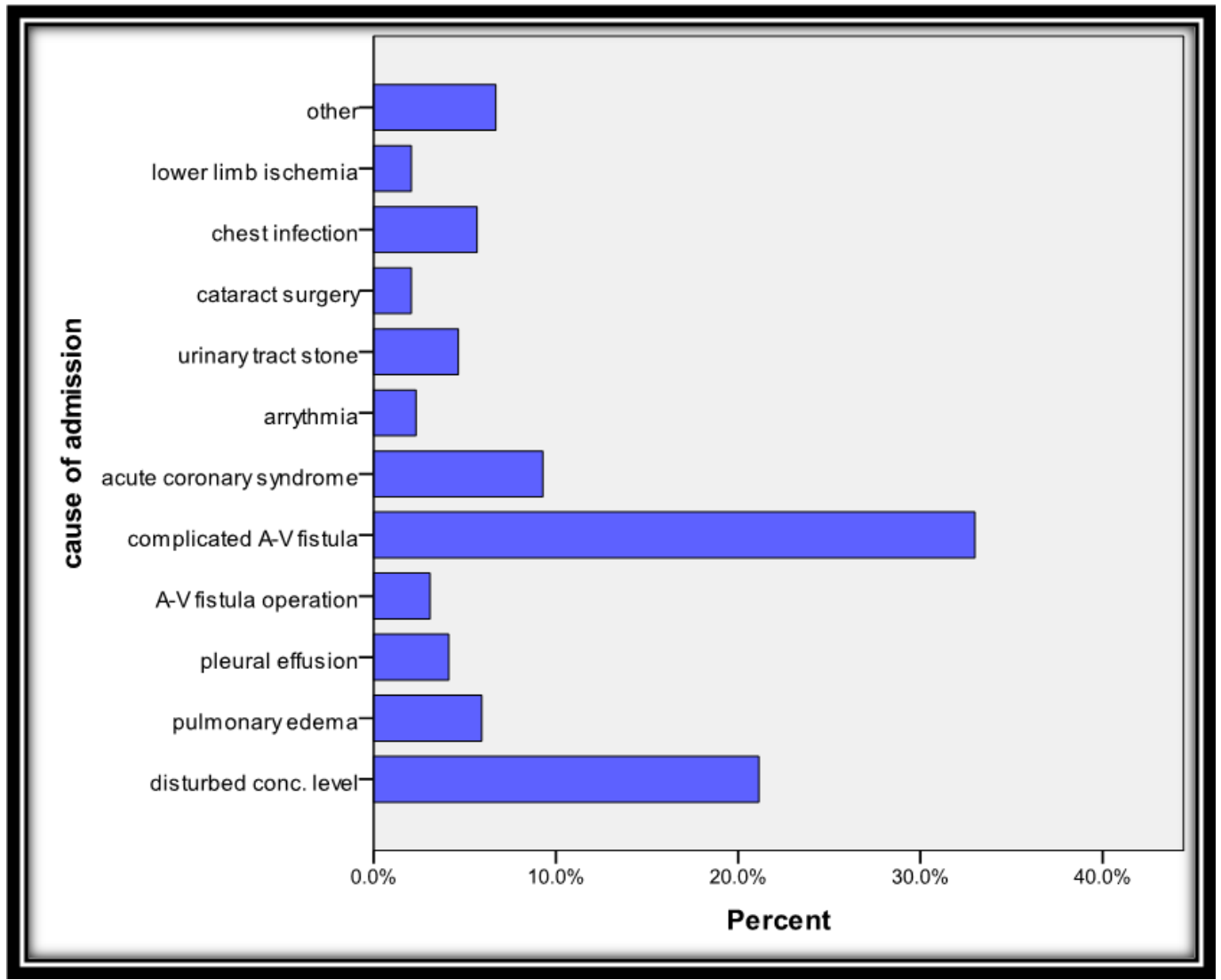

Figure 2: Causes of hospital admission among the studied patients 


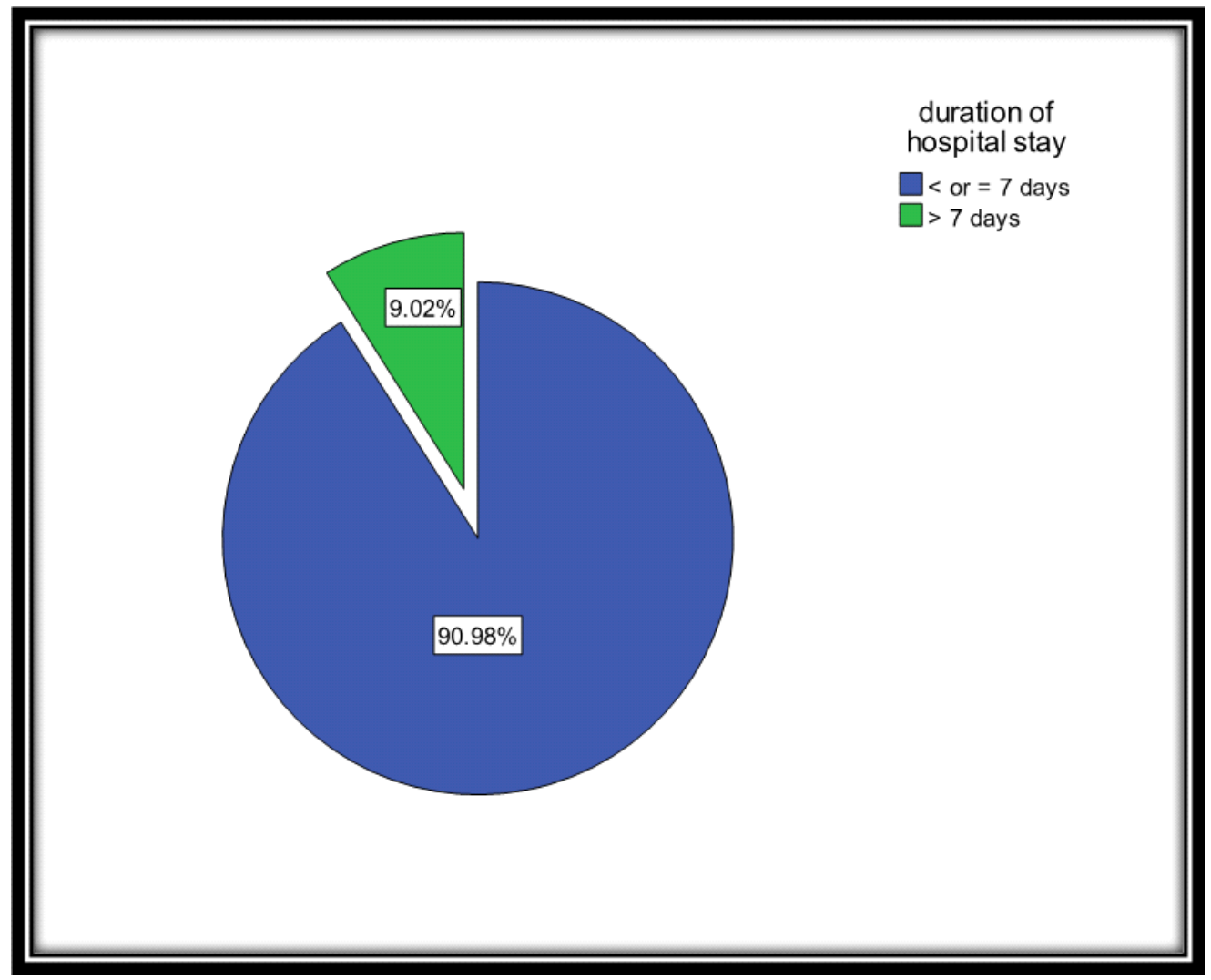

Figure 3: Duration of hospital stay among the studied patients 